\title{
Green Biofuel Production via Catalytic Pyrolysis of Waste Cooking Oil using Malaysian Dolomite Catalyst
}

\author{
R.S.R.M. Hafriz ${ }^{1}$, A. Salmiaton ${ }^{1,2^{*}}$, R. Yunus ${ }^{1}$, Y.H. Taufiq-Yap ${ }^{2}$ \\ ${ }^{1}$ Department of Chemical and Environmental Engineering, Faculty of Engineering, \\ Universiti Putra Malaysia, 43400 UPM Serdang, Selangor, Malaysia \\ ${ }^{2}$ Catalyst Science and Technology Research Center (Putra Cat), Universiti Putra Malaysia, \\ 43400 UPM Serdang, Selangor, Malaysia
}

Received: $13^{\text {rd }}$ December 2017; Revised: $11^{\text {st }}$ June 2018; Accepted: $3^{\text {rd }}$ July 2018; Available online: $14^{\text {th }}$ November 2018; Published regularly: December 2018

\begin{abstract}
Malaysian Dolomite has shown potential deoxygenation catalyst due to high capacity in removing oxygen compound and produce high quality of biofuel with desirable lighter hydrocarbon $\left(\mathrm{C}_{8}-\mathrm{C}_{24}\right)$. The performance of this catalyst was compared with several commercial catalysts in catalytic pyrolysis of Waste Cooking Oil. Calcination at $900{ }^{\circ} \mathrm{C}$ in $\mathrm{N}_{2}$ produced catalyst with very high activity due to decomposition of $\mathrm{CaMg}\left(\mathrm{CO}_{3}\right)_{2}$ phase and formation of $\mathrm{MgO}-\mathrm{CaO}$ phase. The liquid product showed similar chemical composition of biofuel in the range of gasoline, kerosene and diesel fuel. Furthermore, Malaysian Dolomite showed high reactivity with $76.51 \%$ in total liquid hydrocarbon and the ability to convert the oxygenated compounds into $\mathrm{CO}_{2}, \mathrm{CO}, \mathrm{CH}_{4}, \mathrm{H}_{2}$, hydrocarbon fuel gas, and $\mathrm{H}_{2} \mathrm{O}$. Moreover, low acid value $(33 \mathrm{mg} \mathrm{KOH} / \mathrm{g})$ and low aromatic hydrocarbon content were obtained in the biofuel. Thus, local calcined carbonated material has a potential to act as catalyst in converting waste cooking oil into biofuel. Copyright (C) 2018 BCREC Group. All rights reserved
\end{abstract}

Keywords: Malaysian Dolomite; Base Catalyst; Waste Cooking Oil; Catalytic Pyrolysis; Biofuel

How to Cite: Hafriz, R.S.R.M., Salmiaton, A., Yunus, R., Taufiq-Yap, Y.H. (2018). Green Biofuel Production via Catalytic Pyrolysis of Waste Cooking Oil using Malaysian Dolomite Catalyst. Bulletin of Chemical Reaction Engineering \& Catalysis, 13 (3): 489-501 (doi:10.9767/bcrec.13.3.1956.489-501)

Permalink/DOI: https://doi.org/10.9767/bcrec.13.3.1956.489-501

\section{Introduction}

The dwindling reserve of conventional energy resources, challenges of skyrocketing fuel prices and their associated environmental problems have increased the awareness to seek other sustainable and alternative renewable resources for fuel production [1]. Biofuel has recently used as potential fuel to replace the fossil fuel because of its renewability, better gas emis-

\footnotetext{
* Corresponding Author.

E-mail:mie@upm.edu.my (A. Salmiaton)

Telp: +603-89466297, Fax: +603-86567120
}

sions and its biodegradability. Due to current scenario, both edible and non-edible vegetable oils are potential to be used as feedstock in the production of biofuel. However, the cost of feedstock and limited availability of edible vegetable oils are always critical issues for the biofuel production. The exploit of Waste Cooking Oil (WCO) as biofuel feedstock reduces the cost of biofuel production since the feedstock costs constitutes approximately $70-95 \%$ of the overall cost of biofuel production [2,3]. Non-edible oils such as waste cooking oils can be used as a 
cheaper feedstock because of its price 2-3 times cheaper than virgin vegetable oils [4]. In addition, a similarity in the quality of biofuel in a range of biodiesel derived from waste cooking oil and from vegetable oils at an optimum operating condition was reported by Cetinkaya et al. [5].

The production of biofuel can be done using several condition processing for example, at mild temperature process using two-step process esterification-transesterification and at high temperature process using either thermal or catalytic cracking, hydrotreating or hydrocracking. These several condition processes produce a different range of biofuel. Esterification-transesterification process in converting triglyceride based feedstock produce biofuel in a range of biodiesel. However, final product such as pure biodiesel contain high oxygen content (less stable) and can cause serious damage to the engine plug, filter and corrosion to the metal part of process [6]. Meanwhile thermal cracking, catalytic cracking, hydrotreating and hydrocracking will produce wide range of biofuels in a lower oxygen content not only in the range of gasoline and diesel but also in the range of fuel oil or kerosene.

Catalytic cracking or catalytic pyrolysis method offers several advantages over esterification-transesterification reaction including flexibility of feedstock, lower processing costs and compatibility with available infrastructures, engines and fuel standards [7] due to its similarity to that of crude oil processing. Furthermore, the catalytic pyrolysis method enables the selectivity of products. In comparison of hydrogen based processes such as hydrotreating or hydrocracking, these processes are typically more expensive and not economic than catalytic cracking due to unavoidable large amount of hydrogen needed during the processing. Besides, other drawbacks that limit these hydrogen based co-processing is the poisoning of catalyst by water coming from hydrodeoxygenation reactions and the low quality of the resulting hydrogenated product (mainly bad in cold properties). This requires additional conditioning step and cost.

Thermal cracking is a process that possible to crack triglyceride-based feedstock without the presence of hydrogen. But, high amount of oxygenated hydrocarbons is found in the final reaction products and this reduces its interest especially in fuel transport. In contrast, catalytic cracking or catalytic pyrolysis is faster and more selective than thermal cracking which allows working under milder reaction condition and hence maximizing the production of liquid fraction and minimizing yield towards gases, coke, and heavy fraction. Almost null presence of oxygenated compound in the final cracking products is confirmed by different performed studies [8]. Moreover, the presence of catalyst shows a great ability to remove the oxygenated compounds and convert them into $\mathrm{CO}, \mathrm{CO}_{2}, \mathrm{H}_{2} \mathrm{O}$, and mixture of free oxygen hydrocarbon. Catalysts for the pyrolysis process are usually solid catalysts with good shape selectivity and proper size pore. Acid catalysts, such as: HZSM-5, Y-Zeolite, and FCC, have been widely used for hydrocarbon cracking. However, as reported by Wiggers et al. [9], the cracking oils exhibited a high carboxylic acid content which is more than 120 of its acid value. The higher acid value of product have a large effects on the corrosion value, cold filter plugging point and freezing point of pyrolysis oil [7].

Therefore, base catalyst is expected to obtain cracking oils with low acid values and good quality of oil in terms of good cold flow properties. Dolomite is a base catalyst that has been used in catalytic pyrolysis and naturally abundant rock found in several areas of Malaysia. At present, a major domestic usage of dolomite is cement manufacturing and landfill due to its very low cost. Dolomite mainly consists of $\mathrm{CaCO}_{3}$ and $\mathrm{MgCO}_{3}$ with a small amount of ferrite and silica. Like calcite, pure $\mathrm{CaCO}_{3}$, upon a simple calcination at high temperatures, the carbonate groups of dolomite are decomposed, and highly basic $\mathrm{CaO}$ and $\mathrm{MgO}$ are generated. As reported by Asikin-Majid et al. [10], the $\mathrm{CaO}$ and clamshell derives catalyst are potential deoxygenation catalyst for the biofuel production via cracking-decarboxylationdecarbonylation of triolein. In addition, $\mathrm{CaO}$ catalyst could absorb more $\mathrm{CO}_{2}$ either in liquid or solid phase in order to remove oxygen compound via decarboxylation-decarbonylation mechanism. Meanwhile, Putun [11] reported that $\mathrm{MgO}$ plays the important role in increasing the oil quality by reducing oxygen levels from 9.56 to $4.90 \%$ and converting almost all of the long chain alkanes and alkenes to low molecular weight hydrocarbon in diesel range. However, dolomite has received less attention in the basic catalyzed chemical syntheses, in spite of its low cost, high basicity, less toxicity, and environmental friendliness [12]. Therefore, this project is aimed to study heterogeneous catalytic pyrolysis of waste cooking oil over Malaysian Dolomite as a potential deoxygenation catalyst in producing high quality of biofu- 
el in the range of gasoline, kerosene, and diesel.

\section{Materials and Methods}

\subsection{Materials}

Malaysian Dolomite was provided by Northern Dolomite Sdn. Bhd., Perlis and was used as a potential deoxygenation catalyst. Commercial ZSM-5, HY-Zeolite and Fluid Catalytic Cracking (FCC) were purchased from Qingdao Wish Chemicals Co., LTD, Shandong, China, for comparison study. Waste Cooking oil (WCO) was collected from residential area and the oil was centrifuged at $6000 \mathrm{rpm}$ for $30 \mathrm{~min}$ and was then filtered to remove food residue. The oil obtained from centrifuging process was used directly without further purification. Industrial Nitrogen gas was purchased from Smart Biogas Sdn. Bhd. n-Hexane with purity $>98 \%$ was purchased from Merck and was used for GCMS analysis.

\subsection{Catalyst Development}

Dolomite in original form (stone form) was pressed, crushed and ground until they were changed in a fine powder form. The dolomite powder was subjected to size classification using a Retsch Test Sieve in ASTM Ell, $250 \mu$. The Sieved Dolomite powder with particles size below than $0.25 \mathrm{~mm}$ was calcined under flow of industrial nitrogen gas in horizontal tube furnace. The heating rate was set up at $10^{\circ} \mathrm{C} / \mathrm{min}$. The temperature was hold at $900^{\circ} \mathrm{C}$ for 4 hours before cooling down to room temperature. The sieved Malaysian Dolomite powder for both natural and calcined forms were used for characterization. The commercial catalysts, such as: ZSM-5, HY-Zeolite, and Fluid Catalytic Cracking (FCC), were calcined at $700{ }^{\circ} \mathrm{C}$ for 4 hours under flow of industrial nitrogen gas in horizontal tube furnace.

\subsection{Catalyst Characterization}

The thermal decomposition behavior and chemical composition of Malaysian Dolomite was analyzed by using thermogravimetric analyzer (Mettler Toledo, TGA/SDTA851) and wavelength-dispersive XXRF (WDXXRF; model Bruker, S8 TIGER), respectively. The Malaysian Dolomite were characterized before and after calcination by using Diffractometer-XRD System (Shimadzu XRD6000) for the formation of $\mathrm{MgO}-\mathrm{CaO}$ phase and crystalline phase determination. Meanwhile, the physical properties of the Natural Malaysian Dolomite (NMD), calcined Malaysian Dolomite (CMD900), ZSM-5, HY-Zeolite and Fluid Catalytic Cracking (FCC) catalysts, such as: specific surface area, total pore volume and average pore diameter of the samples were determined by BrunauerEmmet-Teller (BET) model using Quantachrome Instrument (model Autosorb-1). The surface and microstructure analysis of these catalysts were carried out using a Scanning Electron Microscope (SEM) instrument equipped with an energy dispersive analyzer (EDX).

\subsection{Catalytic Pyrolysis of WCO}

The thermal and catalytic pyrolysis reactions of Waste Cooking Oil (WCO) were executed at $390{ }^{\circ} \mathrm{C}$ with Industrial $\mathrm{N}_{2}$ gas at heating rate of $100-200 \mathrm{~cm}^{3} / \mathrm{min}$. The evaluation performance of these catalysts were carried out using fractionated cracking system as presented in Figure 1.

In this system, a $44 \mathrm{~cm}$ straight fractionated condenser, gas inlet and thermocouple were attached to three mouthed round bottom flask which serves as the flask reactor. The thermal and catalytic pyrolysis reactions of Waste Cooking Oil (WCO) were carried out using 150 $\mathrm{g}$ of waste cooking. Then the sample catalysts (5 wt \% based on weight of oil) was added to the oil in the flask reactor, and the mixture was stirred to disperse the catalyst in oil. The reaction time was kept at 30 minutes. The gaseous and liquid reaction products leaving the flask reactor were collected separately. The gaseous product was collected by using gas bag for certain time to avoid pressure going up. The liquid product was collected in a collecting flask positioned after the condensing unit. As a result, two liquid fractions and small amount

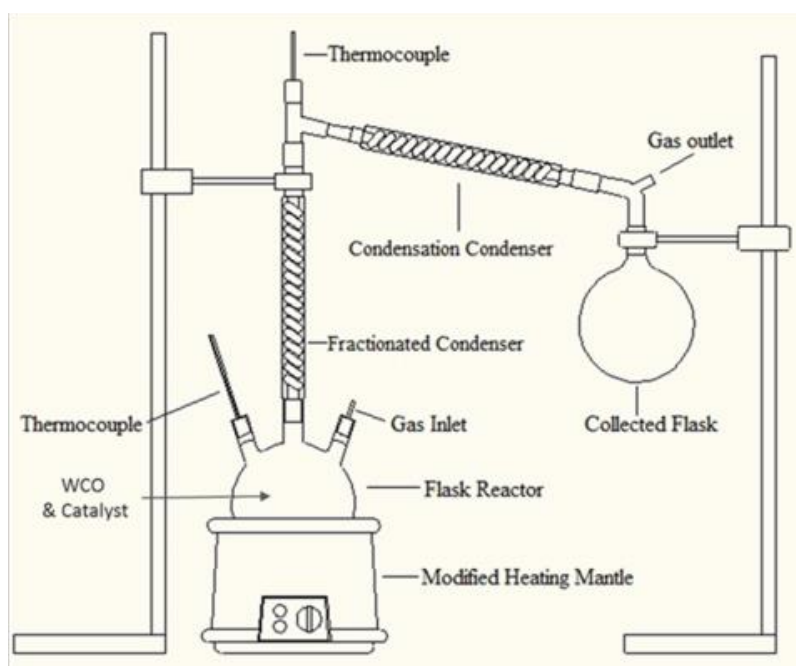

Figure 1. Fractionated cracking system used in the catalytic pyrolysis 
of soap were obtained in the collector flask which are aqueous and organic phases. These phases were separated by decantation. The amount of the collected liquid, gas, and residual oil-coke were measured. Pyrolysis oil and gas product were further analyzed using GC-MS, FT-IR and GC-TCD. The Equations (1) and (2) were used to calculate the mass balance:

$$
\begin{aligned}
& \text { Yield of pyrolysisoil }(w t \%)=\frac{y}{w} \times 100 \% \\
& \text { Conversion of } W C O(w t \%)=\frac{w-r}{w} \times 100 \%
\end{aligned}
$$

where $w$ is mass of waste cooking oil (g), $r$ is mass of coke $(\mathrm{g})$, and $y=$ mass of pyrolysis oil (g). Meanwhile, mass of coke $(r)$ can be calculated using Equation 3 [13].

$$
r=w_{1}-w_{2}
$$

where $w_{1}$ is residue in the reactor after the pyrolysis reaction including coke formation on the reactor and on the catalyst, and some amount of unreacted oil suspended with the catalyst minus the mass of the reactor, and $w_{2}$ is mass of fresh catalyst before the reaction.

\subsection{Analysis of Pyrolysis Oil and Gas}

Gas Chromatography-Mass Spectrometry (GC-MS) was used to analyze the composition of Pyrolysis Oil. The separation of Pyrolysis Oil were qualitatively and quantitatively analyzed in a non-polar ZB-5MS column $(30 \mathrm{~m} \times 0.25$ $\mathrm{mm}$ I.D $\times 0.25 \mu \mathrm{m}$ film thickness) in a split mode. The oven temperature was programmed to hold at $40{ }^{\circ} \mathrm{C}$ for $3 \mathrm{~min}$, ramp at $7^{\circ} \mathrm{C} / \mathrm{min}$ to $300{ }^{\circ} \mathrm{C}$ and hold at $300{ }^{\circ} \mathrm{C}$ for $5 \mathrm{~min}$. The injector temperature was set at $250{ }^{\circ} \mathrm{C}$ and the flow rate of the He carrier gas was $3.0 \mathrm{~mL} / \mathrm{min}$. Different class of compound presented in Pyrolysis Oil were identified using National Institute of Standards and Testing (NIST) library. Identification was carried out according to preestablish criteria for analysis of the data. Total product yield and product selectivity was determined by comparing the peak area in percentage (\%) of obtained spectra presented. GC-MS analysis as known does not provide exact quantitative analytic result of compounds but it is actually possible to compare the product yield and product selectivity by comparing the peak areas as the chromatographic peak area of compounds is proportional to its quantity and the relative content of the product based on equations (4) and (5) below.
The FTIR spectra instrument (model Perkin-Elmer 100 series, USA) was used to determine the functional group of pyrolysis oil. The spectral data was used to identify the compounds by mating the fingerprint of the samples with those in the database. In addition, the functional groups and the structural characterization of compounds enabled us to elucidate the possible structural types. The spectrum range of the FTIR was the mid-infrared region, which covers the frequency ranges of $500-4000 \mathrm{~cm}^{-1}$. A GC-TCD was used to analyze the composition of gas produced from Catalytic Pyrolysis of WCO. The gas produced was collected using the Tedlar gas bags equipped with rubber septum for certain reaction time and certain temperature. To determine the gas composition in general, a fixed $1 \mathrm{~mL}$ of gas was removed from the gas bag using a gastight syringe (Hamilton, USA). The gas was then injected to a gas chromatography (HP6890N, Agilent Technologies, USA) equipped with a thermal conductivity detector (TCD) and Carboxen 1010 PLOT $(30 \mathrm{~m} \times 0.53 \mathrm{~mm}$ I.D) column (Supelco, 25467, USA).

$$
\text { Product yield }(\%)=\frac{\text { Area of } C_{8}-C_{24}}{\text { Total area of the product }} \times 100 \%
$$

Product selectivity $(\%)=\frac{\text { Area of desired product }}{\text { Total area of the product }} \times 100 \%$

\section{Results and Discussion}

\subsection{Thermal Decomposition Behavior}

The thermal decomposition behavior of Natural Malaysian Dolomite (NMD) was conducted using thermogravimetric analyzer as shown in Figure 2. The slope of TGA curve decreased as the temperature increased and starting constant at temperature above $860{ }^{\circ} \mathrm{C}$. No decomposition of Malaysian Dolomite was observed at high temperature. Thus, it was suggested that Malaysian Dolomite should be calcined at high temperature $\left(>900{ }^{\circ} \mathrm{C}\right)$. The natural Malaysian Dolomite (NMD) shows $49.13 \%$ weight loss at $409-860^{\circ} \mathrm{C}$. The derivative thermogravimetric, DTG curve indicates two major peaks of decomposition and this can be attributed to the decomposition of the carbonates mineral through releasing of $\mathrm{CO}_{2}$ in high temperature of calcination.

Malaysian Dolomite in a form of double carbonate of Calcium and Magnesium, $\mathrm{CaMg}\left(\mathrm{CO}_{3}\right)_{2}$ is often assumed to be decomposed in two separate peak represented in chemical Equations (6), (7), and (8). As reported by Tau- 
fiq-Yap et al. [14], both separation peak occurs in different stages of thermal temperature which are based on enthalpy energy of each component. The first peak begins at $409{ }^{\circ} \mathrm{C}$, reaches a maximum at $785^{\circ} \mathrm{C}$ and ends at 805 ${ }^{\circ} \mathrm{C}$ whereas the second peak begins at $810{ }^{\circ} \mathrm{C}$ reaches a maximum at $837^{\circ} \mathrm{C}$ and ends at 860 ${ }^{\circ} \mathrm{C}$.

First peak:

$\mathrm{CaMg}\left(\mathrm{CO}_{3}\right)_{2} \underset{(\mathrm{s})}{\stackrel{810^{\circ} \mathrm{C}}{\rightarrow} \mathrm{CaCO}_{3(\mathrm{~s})}+\mathrm{MgCO}_{3}(\mathrm{~s})}+2 \mathrm{C}_{3} \mathrm{H}_{6} \mathrm{O}$

$\mathrm{MgCO}_{3} \stackrel{4 \mathrm{~s})}{\stackrel{490^{\circ} \mathrm{C}}{\rightarrow}} \mathrm{MgO}(\mathrm{s})+\mathrm{CO}_{2}(\mathrm{~g})$

Second Peak:

$\mathrm{CaCO}_{3} \stackrel{58 \mathrm{~s}^{\circ}}{\rightarrow} \mathrm{CaO}(\mathrm{s})+\mathrm{CO}_{2}(\mathrm{~g})$

The first peak at lower temperature represent the decomposition of the dolomite structure by releasing $\mathrm{CO}_{2}$ to form $\mathrm{CaCO}_{3}$ and $\mathrm{MgO}$. At high temperature, the second peak observed corresponds to the decomposition of calcite to form $\mathrm{CaO}$, with releasing $\mathrm{CO}_{2}$. As a result, the thermal treatment process at $900{ }^{\circ} \mathrm{C}$ was selected as temperature for calcination of Natural Malaysian Dolomite (NMD) under flow of nitrogen due to disappearance of the $\mathrm{CaMg}\left(\mathrm{CO}_{3}\right)_{2}$ phase and the successful formation of $\mathrm{MgO}$ $\mathrm{CaO}$ phase which act as potential deoxygenation catalyst of WCO.

\subsection{Chemical Composition Analysis}

The chemical composition of Calcined Malaysian Dolomite (CMD900) were determined using wavelength-dispersive XRF and listed in Table 1.

The composition of calcined Malaysian Dolomite in this study are similar with Malaysian Dolomite catalyst, P1 reported by Mohammed et al. [15] in biomass gasification process. The main content of this Malaysian Dolomite are $\mathrm{CaO}$ (31.0 \%), MgO (20.0\%), and small amount of undesirable impurities, such as: $\mathrm{SiO}_{2}, \mathrm{MnO}$, $\mathrm{K}_{2} \mathrm{O}, \mathrm{Na}_{2} \mathrm{O}$, and $\mathrm{Al}_{2} \mathrm{O}_{3}$. The formation of $\mathrm{CaO}$ and $\mathrm{MgO}$ indicated that Malaysian Dolomite could convert triglycerides of $\mathrm{WCO}$ to long chain hydrocarbons in a gasoline and diesel range. Mohammed et al. [15] reported that these undesirable impurities combine with $\mathrm{CaO}$ to form a slag under elevated tempera-

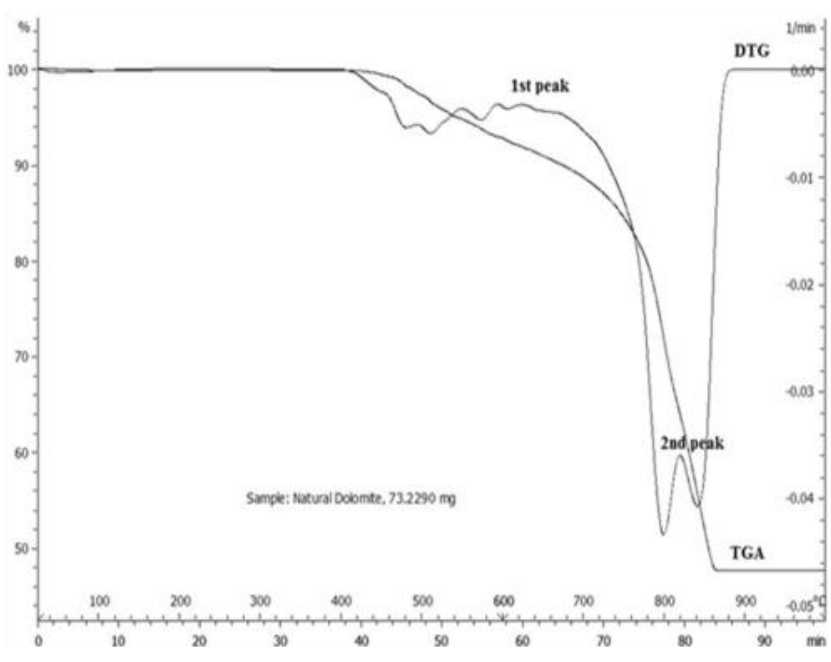

Figure 2. Thermogravimetric analysis and derivative thermogravimetric curves of Natural Malaysian Dolomite

Table 1. Chemical composition of Malaysian dolomite (\%)

\begin{tabular}{ccc}
\hline Compounds (\%) & Malaysian Dolomite [15] & $\begin{array}{c}\text { Malaysian Dolomite } \\
\text { (This study) }\end{array}$ \\
\hline $\mathrm{SiO}_{2}$ & 0.07 & 0.06 \\
$\mathrm{Al}_{2} \mathrm{O}_{3}$ & 0.04 & 0.02 \\
$\mathrm{Fe}_{2} \mathrm{O}_{3}$ & 0.07 & 0.08 \\
$\mathrm{CaO}$ & 30.0 & 31.0 \\
$\mathrm{MgO}$ & 21.0 & 20.0 \\
$\mathrm{~K}_{2} \mathrm{O}$ & 0.014 & 0.02 \\
$\mathrm{Na}_{2} \mathrm{O}$ & 0.013 & 0.015 \\
$\mathrm{P}_{2} \mathrm{O}_{5}$ & 0.013 & 0.012 \\
$\mathrm{MnO}$ & 0.01 & 0.04 \\
$\mathrm{SrO}$ & 0.008 & 0.008 \\
$\mathrm{TiO}_{2}$ & 0.006 & 0.009 \\
$\mathrm{SiO}_{2}$ & 0.07 & 0.06 \\
\hline
\end{tabular}


tures resulted in a decreasing in pore volume and amount of available active site.

\subsection{Phase Change Analysis}

The XRD diagrams of Malaysian Dolomite before and after calcined are presented in Figure 3. After calcination at $900{ }^{\circ} \mathrm{C}$ under flow of nitrogen gas, the XRD pattern for calcined Malaysian Dolomite (CMD900) changed drastically compared to natural Malaysian Dolomite (NMD). New dominant peaks of $\mathrm{CaO}$ (JCPDS 82-1691) and $\mathrm{MgO}$ (JCPDS 89-4248) were observed due the formation of $\mathrm{MgO}-\mathrm{CaO}$ form in XRD pattern of calcined Malaysian Dolomite (CMD900), which is the active catalytic component in removing oxygen compounds. Whereas, the natural Malaysia Dolomite (NMD), in XRD pattern showed that all peaks correspond to the $\mathrm{CaMg}\left(\mathrm{CO}_{3}\right)_{2}$ (JCPDS 36-0426). While, the small additional peaks of $\mathrm{SiO}_{2}$ (JCPDS 35-0063), $\mathrm{TiO}_{2}$ (JCPDS 76-0326) and $\mathrm{Fe}_{2} \mathrm{O}_{3}$ (JCPDS 89-0597) were also observed, occurring at $2 \theta$ of $28^{\circ}, 72^{\circ}$, and $74^{\circ}$, respectively. All peaks were also observed in research work conducted by Mohammed et al. [15].

\subsection{Surface Area and Total Pore Volume Analy-} sis

The BET surface area, pore volume and average pore size for Natural Malaysian Dolomite (NMD), calcined Malaysian Dolomite (CMD900), ZSM-5, HY-Zeolite, and Fluid Catalytic Cracking (FCC) are summarized in Table 2. The calcined Malaysian Dolomite generated an increase specific surface area and a decrease in the particle size during the decarbonation process. The surface area and pore volume of calcined Malaysian Dolomite (CMD900) has increased from $2.25 \mathrm{~m}^{2} / \mathrm{g}$ to $12.02 \mathrm{~m}^{2} / \mathrm{g}$ and 0.06 $\mathrm{cm}^{3} / \mathrm{g}$ to $0.24 \mathrm{~cm}^{3} / \mathrm{g}$, respectively, due to thermal activation at $900{ }^{\circ} \mathrm{C}$. Based on Mohammed et $a l$. [15], the increasing of surface area and pore volume are possibly due to the high formation $\mathrm{CaO}$ and $\mathrm{MgO}$ content and removing of undesirable impurities, such as: $\mathrm{SiO}_{2}, \mathrm{MnO}, \mathrm{K}_{2} \mathrm{O}$, $\mathrm{Na}_{2} \mathrm{O}$, and $\mathrm{Al}_{2} \mathrm{O}_{3}$, in calcined Malaysian Dolo- mite. A reduction of $58 \%$ in average pore diameter of calcined Malaysian Dolomite was observed due to decomposition of carbonates mineral and the release of $\mathrm{CO}_{2}$ as represented in Equations (2) and (3). The increasing of surface area are greater in FCC $>$ HY-Zeolite $>$ ZSM-5 > CMD900 > NMD, respectively. Increased surfaces area of the catalyst improves yield of pyrolysis oil due to increasing the rate of reaction by increasing the chances of collision between WCO molecules with the active site. Meanwhile, the average pore size is bigger in sequence of catalysts; NMD > CMD900 > FCC $>$ ZSM-5 $>$ HY-Zeolite. The bigger average pore size presence on surface area of catalyst, the higher possibility of coke formation due to the partial blockage of pores catalyst by carbon formation over the catalyst as shown in Table 3.

\subsection{Surface Morphology Analysis}

Scanning Electron Microscopy (SEM) images at $10 \mathrm{~K}, 30 \mathrm{~K}$, and $60 \mathrm{~K}$ times of magnification for all catalysts are presented in Figure 4. The notably change in the external morphology of the Natural Malaysian Dolomite (NMD) and Calcined Malaysian Dolomite (CMD) were il-

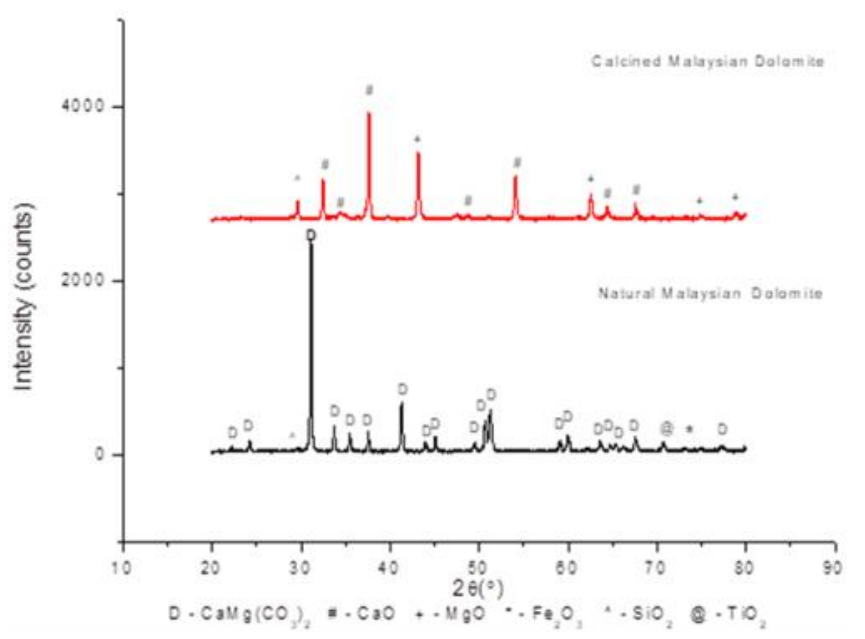

Figure 3. X-ray diffraction pattern of Malaysian Dolomite before and after calcination

Table 2. Physicochemical properties of all catalysts

\begin{tabular}{lccccc}
\hline \multicolumn{1}{c}{ Characterization } & NMD & CMD900 & ZSM-5 & HY-Zeolite & FCC \\
\hline BET surface area $\left(\mathrm{m}^{2} / \mathrm{g}\right)$ & 2.25 & 12.02 & 30.95 & 33.27 & 59.99 \\
Pore volume $\left(\mathrm{cm}^{3} / \mathrm{g}\right)$ & 0.06 & 0.24 & 0.07 & 0.08 & 0.11 \\
Average pore diameter $(\mathrm{nm})$ & 109.41 & 63.07 & 1.22 & 1.22 & 2.41 \\
\hline
\end{tabular}

Determined by using BET analysis 
lustrated in Figure 4 (NMD-a, b, c \& CMD-e, f, g). The micrograph in SEM analysis showed that natural Malaysian Dolomite have a rough and disordered surface with low porosity grain meanwhile, calcined Malaysian Dolomite shows cluster of tidy and higher porosity of grains on the surface. Simultaneously, the surface area and the pore volume of calcined Malaysian Dolomite increased significantly due to effect on thermal decomposition and activation at 900 ${ }^{\circ} \mathrm{C}$. Report by Yoosuk et al. [16], the increasing in surface area upon calcination has been attributed to the formation of pores due to the expulsion of $\mathrm{CO}_{2}$ via the decarbonation of $\mathrm{CaMg}\left(\mathrm{CO}_{3}\right)_{2}$. Zeolite have found use in petroleum refineries almost 50 years ago due their high activity to hydrocarbon cracking coupled to shape selectivity provided by their pore structure and morphology [17]. They achieved a higher relative aromatics content which can increase the product octane number by producing less gas. This can be seen from the composition profile of liquid hydrocarbon (Table 4) which can relate to high formation of aromatic content (ZSM5-6.51 \% and HY-zeolite $3.28 \%$ ).

Figure 4 (ZSM-5-g, h, i) shows a disordered hexagonal plate shape in calcined ZSM-5 with BET surface area around $30.95 \mathrm{~m}^{2} / \mathrm{g}$ and quite similar with BET surface area $\left(33.27 \mathrm{~m}^{2} / \mathrm{g}\right)$ of calcined HY-Zeolite which have a smooth octagonal shape (HY-Zeolite-Figure 4-j, k, l). Calcined FCC shows a fines spherical particle on a surface providing a highest BET surface area $\left(59.99 \mathrm{~m}^{2} / \mathrm{g}\right)$ and pore volume $\left(0.11 \mathrm{~cm}^{3} / \mathrm{g}\right.$ as shown in Figure 4 (FCC-m, n, o). Moreover, FCC catalyst appears to be the bimodal pore size distribution arising from the combination of microporous and mesoporous structure [18]. As result, the performance of FCC catalyst appear significantly better than ZSM-5 and HYzeolite in yield of pyrolysis oil as presented in Table 3.

\subsection{Catalytic Pyrolysis of WCO}

The thermal and catalytic pyrolysis of Waste Cooking Oil (WCO) were conducted to scrutinize the performance of these catalysts in terms of the yield of Pyrolysis Oil and conversion of WCO. The reaction without using catalyst, known as thermal cracking, was also conducted in this studies. The product distribution and conversion of WCO to pyrolysis oil (biofuel) were measured using mass balance in a unit weight percent (wt \%). Based on product distribution of WCO pyrolysis over various catalysts as shown in Figure 5 and Table 3, the pyrolysis using FCC catalyst generated high yield of pyrolysis oil (25.10 wt\%) followed by using ZSM-5 (23.25 wt\%) > CMD900 (13.37 wt\%) > HYZeolite (10.92 wt\%). The presence of high surface area and bimodal pore size distribution exhibited by FCC catalyst [18] provide the efficient access and molecular transport of WCO into FCC active site under mild operation condition.

Meanwhile, in thermal pyrolysis reaction, the yield of pyrolysis oil was very low (1.73 wt\%). This shows that catalytic pyrolysis is faster and more selective than thermal cracking which allows working under milder reaction condition and hence maximizing the production of liquid fraction. The FCC and HYZeolite shows a higher conversion of WCO followed by ZMS-5, Thermal, and CMD900. Large average pore diameter of a catalyst can lead to faster catalyst deactivated due to large quantity of coke formation on the catalyst surface during the pyrolysis process.

The deactivation of the catalyst activity will affect the conversion of WCO to pyrolysis oil in a range of gasoline, kerosene and diesel. In catalytic pyrolysis of WCO using CMD900, the yield of pyrolysis oil was greater than commercial catalyst, HY-Zeolite due to high presence of CaO-MgO phase. As reported by Srinakru-

Table 3. Catalytic performance of various catalyst in the thermal and catalytic pyrolysis of WCO under mild reaction condition $\left(390{ }^{\circ} \mathrm{C}, 30\right.$ minutes, $\left.\mathrm{N}_{2}=100 \mathrm{~cm}^{3} / \mathrm{mins}\right)$

\begin{tabular}{lccccc}
\hline Catalysts & Thermal & CMD900 & ZSM-5 & HY-Zeolite & FCC \\
\hline Conversion of WCO (wt\%) & 38.00 & 35.99 & 44.33 & 51.66 & 51.00 \\
Liquid Product (wt\%) & 2.00 & 21.23 & 25.28 & 12.47 & 27.99 \\
Pyrolysis Oil (wt\%) & 1.73 & 13.37 & 23.25 & 10.92 & 25.10 \\
Soap Formed (wt\%) & 0.00 & 4.84 & 0.00 & 0.00 & 0.00 \\
Acid Phase (wt\%) & 0.27 & 3.02 & 2.03 & 1.55 & 2.89 \\
Gas Product (wt\%) & 36.00 & 14.76 & 19.05 & 39.19 & 23.01 \\
Coke (wt\%) & 62.00 & 64.01 & 55.67 & 48.34 & 49.00 \\
\hline
\end{tabular}



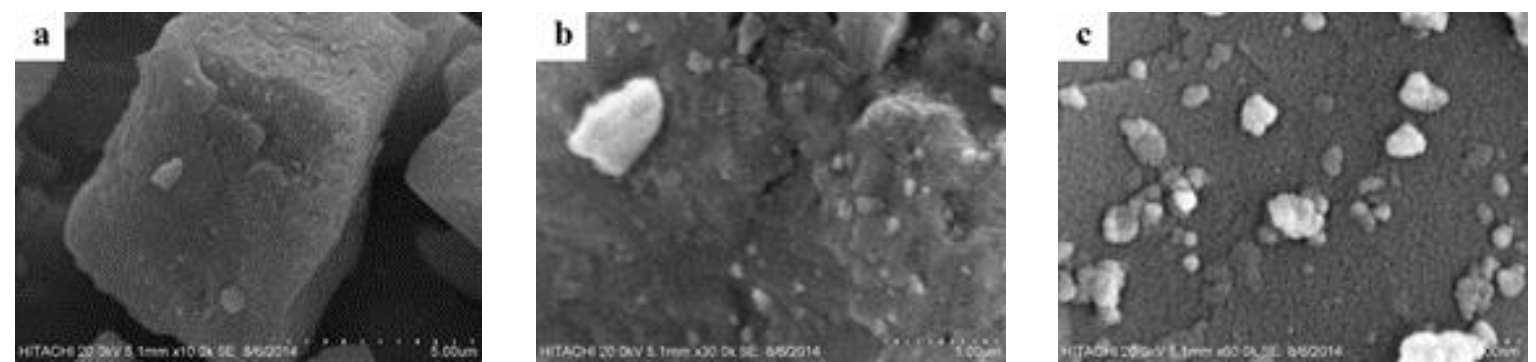

Natural Malaysian Dolomite (magnification x10k, 30k \& 60k)
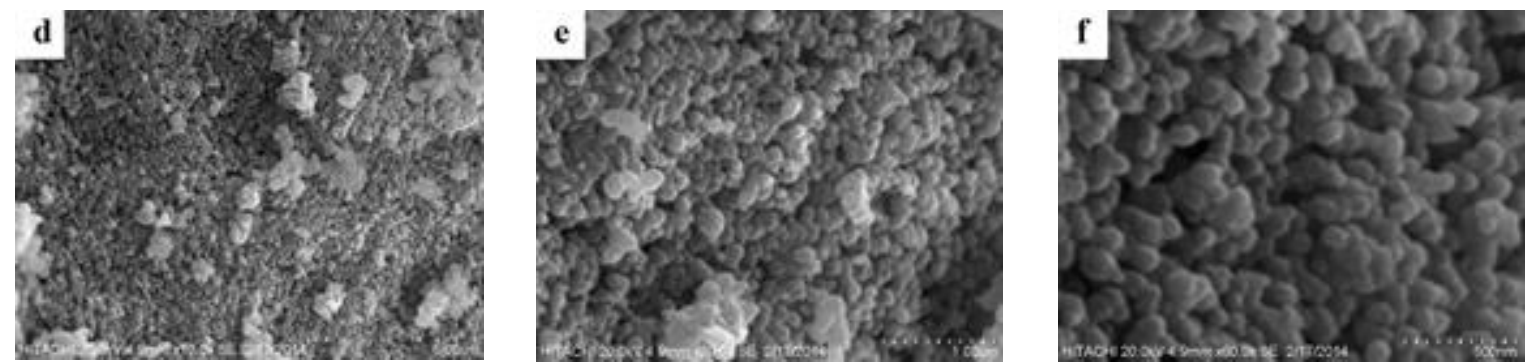

Calcined Malaysian Dolomite (NMD) (CDM900) (magnification x10k, 30k \& 60k)
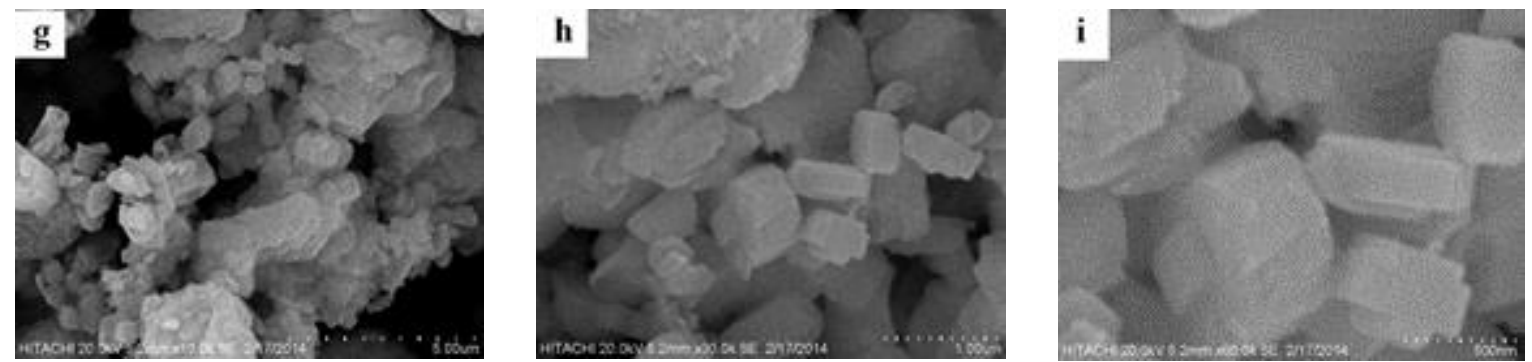

Calcined ZSM-5 (magnification x10k, 30k \& 60k)
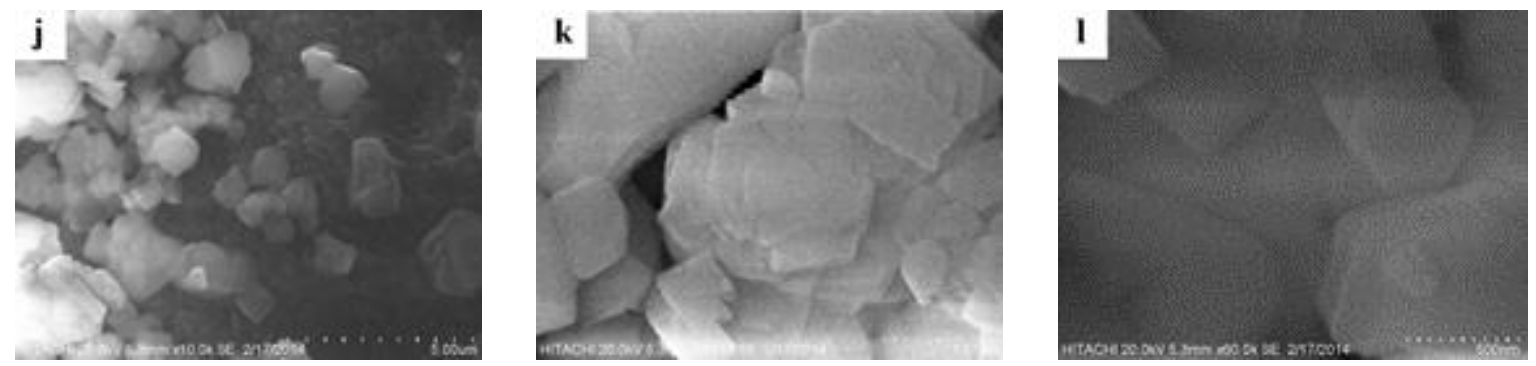

Calcined HY-Zeolite (magnification x10k, 30k \& 60k)
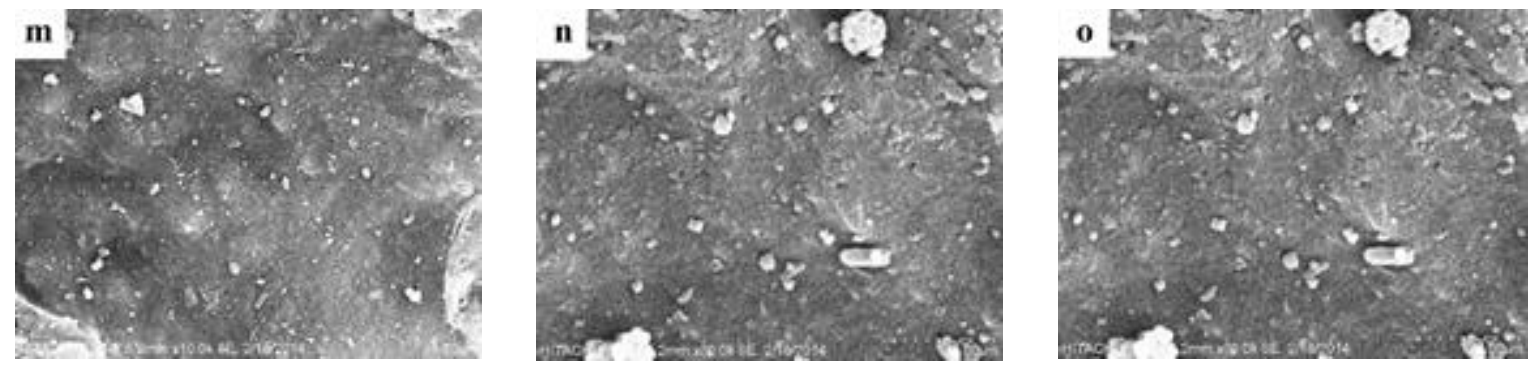

Calcined HY-Zeolite (magnification x10k, 30k \& 60k)

Figure 4. Scanning Electron Microscopy (SEM) images at 10k, 30k and 60k times magnification for all catalysts 
ang et al. [19], the dolomite would only be active in the calcined form $(\mathrm{CaO}-\mathrm{MgO})$, whereby the transformation occurred around $850^{\circ} \mathrm{C}$ under atmospheric pressure. Waste cooking oil contains high free fatty acid content than the fresh cooking oils. Hence, it is known that higher free fatty acid contents will lead to formation of soap. The small formation of soap (salt) as by product was found in these reaction, possibility created by hydrolysis (saponification) of fatty acid with the base catalyst. The finding was similar with Maher and Bressler [20], the salt (soap) was produced when $\mathrm{CaO}$ was first reacted with fatty acid which was then further decomposed into hydrocarbons and by product. The yield of pyrolysis oil would be reduced as a result of the soap formation during the pyrolysis process as shown in Table 3. However, based on various catalysts used, CMD900 still show potential catalyst to be used in converting triglyceride-WCO into high quality of biofuel in the range of gasoline, kerosene and diesel.

\subsection{Chemical Composition of Pyrolysis Oil and Gas}

\subsubsection{Hydrocarbon group analysis}

The composition of pyrolysis oil using different type of catalysts in catalytic pyrolysis can be determined by comparing the GC-MS peak area \% of hydrocarbon and oxygenated compound as shown in Figure 6. Based on the result, pyrolysis oil produced by using CMD900 as catalyst shows high amount of hydrocarbon with $76.51 \%$ and lower amount of oxygenated compound (23.49\%). The CMD900 shows a great ability to remove the oxygenated compounds and convert them into $\mathrm{CO}_{2}, \mathrm{CO}, \mathrm{H}_{2} \mathrm{O}$, and mixture of free oxygen hydrocarbon due to

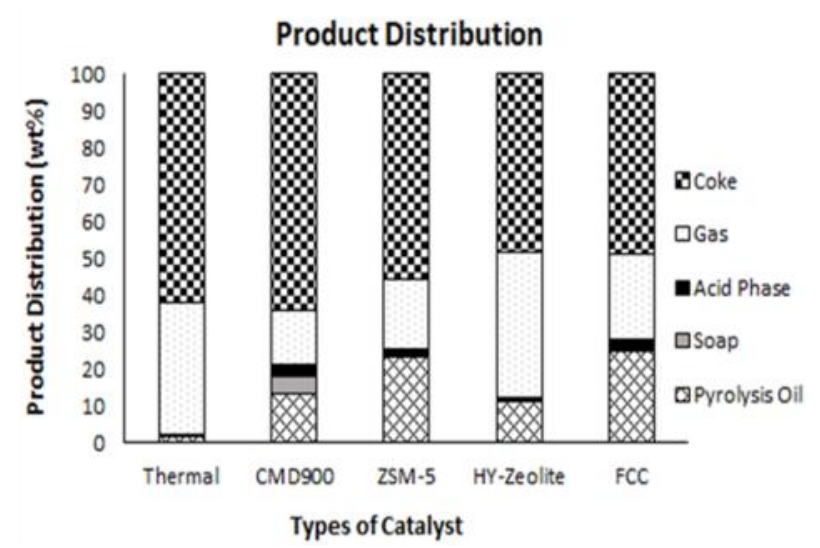

Figure 5. Product distribution in thermal and catalytic pyrolysis of WCO formation of $\mathrm{CaO}-\mathrm{MgO}$ phase. This is in agreement with Asikin-Majid et al. [10] where the researchers reported that $\mathrm{Ca}$ based catalyst acted as deoxygenation catalyst due to its relatively high capacity in removing oxygenated compound in the form of $\mathrm{CO}_{2}$ and $\mathrm{CO}$ under decarboxylation and decarbonylation reaction respectively. Moreover, as reported by Taufiq Yap et al. [14], the presence of $\mathrm{CaO}$ phase in the Dolomite gave additional advantages in tar cracking and $\mathrm{CO}_{2}$ absorption. Meanwhile, the presence of $\mathrm{MgO}$ phase would enhance the strength of dolomite particle structure, which provides additional void space and a continuous free passage for $\mathrm{CO}_{2}$ diffusion to the interior dolomite catalyst $[21,22]$. Figure 7 shows total composition of hydrocarbon chain length from $\mathrm{C}_{8}-\mathrm{C}_{24}$ determined by peak area \% of GCMS.

Based on the result, high yield of hydrocarbon chain length from $\mathrm{C}_{8}-\mathrm{C}_{24}$ was found in the pyrolysis oil using CMD900 followed by Thermal $>$ ZSM-5 > HY-Zeolite $>$ FCC. Even though the yield of pyrolysis oil using CDM900 was lower, the quality of this pyrolysis oil was extremely good due to basicity of active sites from CDM900 which made the absorption of $\mathrm{CO}_{2}$ gas during deoxygenation reaction was more effective in $\mathrm{CaO}-\mathrm{MgO}$ phase in $\mathrm{CMD} 900$. In addition, based on the composition profile of liquid hydrocarbon as shown in Table 4, the presence of straight alkane and alkene in pyrolysis oil using CMD900 was higher with $23.71 \%$ alkane and $35.09 \%$ alkene.

The formation of branch alkanes in CMD900 product was also higher compared to others and the formation of long chain alkanes into these branched alkanes was the final step to enhance the fuel quality. It was known long

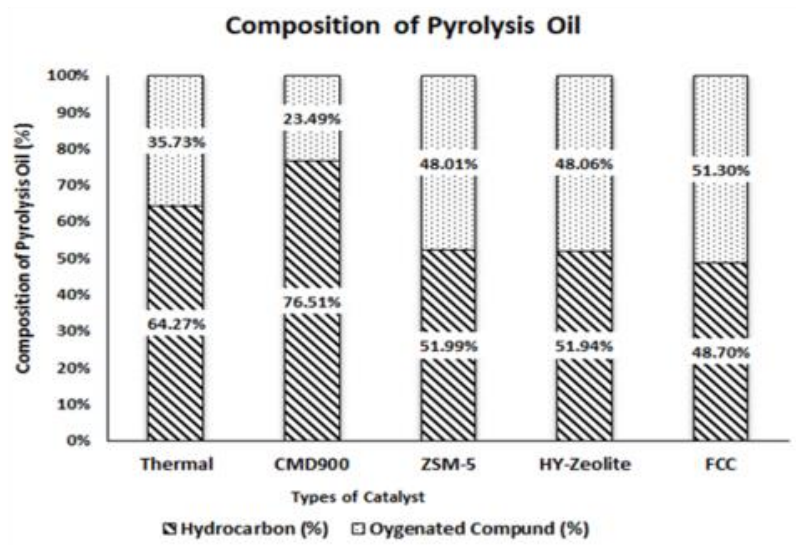

Figure 6. The composition of pyrolysis oil using different catalysts in Catalytic Pyrolysis reaction of $\mathrm{WCO}$ 
ago that straight hydrocarbons are prone to induce engine knock (uncontrolled combustion) than highly branched or cyclic compound. This is due to straight hydrocarbon contain lower octane number making them burns so poorly in engines. The more branched hydrocarbon is, the higher the octane number. The small formation of cycloalkane, cycloalkene, diene, alkyne and aromatic could be observed in the composition of pyrolysis oil using all commercial catalysts especially ZSM-5 which favored aromatic rich liquid hydrocarbon production. Meanwhile, the CMD900 produced not only a low formation of oxygenated compound but also generated a low amount of aromatic hydrocarbon content in the pyrolysis oil compared to the others. This is considered an advantage because of the carcinogenic effect from aromatics compound in fuels as targeted by 'European Programme on Emission Fuels and Engine Technologies' to reduce benzene content of fuel.

The pyrolysis oil generated form WCO pyrolysis using commercial catalyst, such as: FCC, ZSM-5, or HY-Zeolite, contains high amount of carboxylic acid group in oxygenated compound which slightly increase acid value of pyrolysis oil. The high acid value was obtained

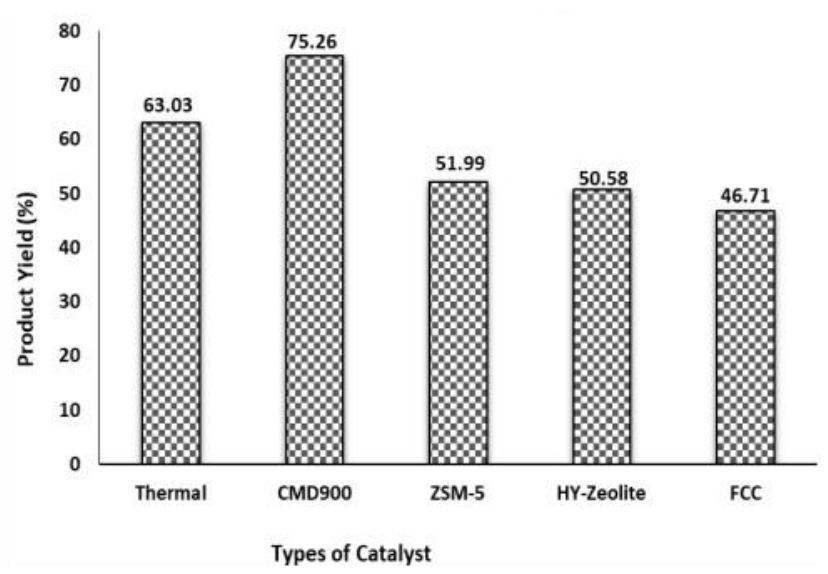

Figure 7. Total composition of hydrocarbon chain length from $\mathrm{C}_{8}-\mathrm{C}_{24}$ with the presence of large amount of carboxylic acid group in oxygenated compound as shown in Table 5. The acid value of pyrolysis oil generated from non-catalytic WCO pyrolysis was found higher compared to catalytic WCO pyrolysis with thermal (186 mg KOH/ g) > ZSM-5 (156 mg KOH/ g) > FCC (151 mg KOH/ g) > HY-Zeolite (129 mg KOH/ g) > CMD900 (33 mg $\mathrm{KOH} / \mathrm{g})$. Acid value of pyrolysis oil decrease to 16 until $82 \%$ with the presence of acid and base catalyst, respectively. As reported by Wiggers et al. [9], the cracking oils using acid catalyst exhibited a high carboxylic acid content (higher acid value) which gave a large effects on the corrosion value, cold filter plugging point and freezing point of pyrolysis oil.

The degree of selectivity for each catalyst towards gasoline, kerosene and diesel range obtained from deoxygenation reaction of $\mathrm{WCO}$ is shown in Figure 8. The selectivity was selected based on carbon number of hydrocarbon content in pyrolysis oil. Based on the result shown in Figure 8, pyrolysis oil generated using CMD900 and thermal were mostly in light hydrocarbon which is in the gasoline range carbon number.

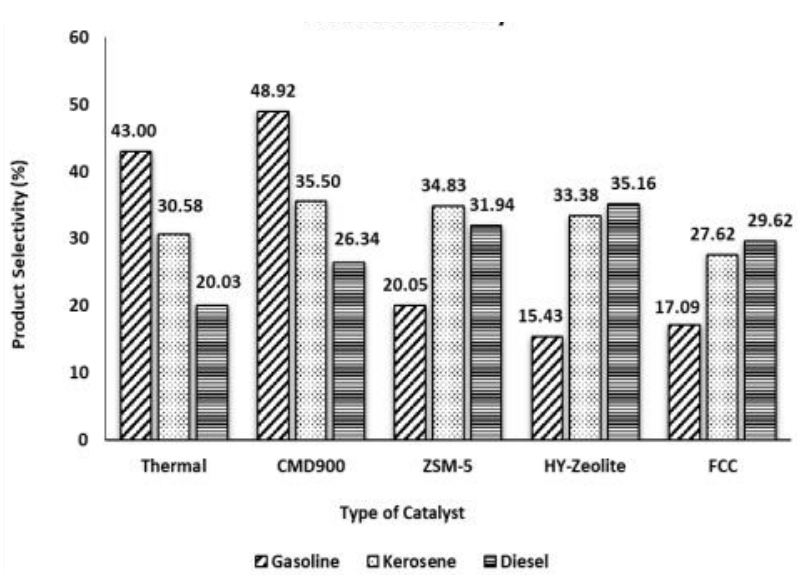

Figure 8. Selectivity in liquid hydrocarbon product produced in catalytic pyrolysis of WCO

Table 4. Composition profile of liquid hydrocarbon in pyrolysis oil

\begin{tabular}{ccccccccc}
\hline Catalyst & $\begin{array}{c}\text { Total Hydrocar- } \\
\text { bon Product (\%) }\end{array}$ & $\begin{array}{c}\text { Alkane } \\
(\%)\end{array}$ & $\begin{array}{c}\text { Cycloalkane } \\
(\%)\end{array}$ & $\begin{array}{c}\text { Alkene } \\
(\%)\end{array}$ & $\begin{array}{c}\text { Cycloal- } \\
\text { kene (\%) }\end{array}$ & $\begin{array}{c}\text { Diene } \\
(\%)\end{array}$ & $\begin{array}{c}\text { Alkyne } \\
(\%)\end{array}$ & $\begin{array}{c}\text { Aro- } \\
\text { matic } \\
(\%)\end{array}$ \\
\hline Thermal & 64.27 & 17.39 & 6.73 & 27.37 & 5.37 & 0.06 & 0.89 & 6.46 \\
CMD900 & 76.51 & 23.71 & 10.22 & 35.09 & 4.67 & 0.77 & 0.48 & 1.57 \\
ZSM-5 & 51.99 & 21.46 & 6.86 & 15.58 & 1.58 & 0.00 & 0.00 & 6.51 \\
HY-Zeolite & 51.94 & 26.01 & 4.09 & 14.73 & 2.55 & 0.32 & 0.96 & 3.28 \\
FCC & 48.70 & 21.65 & 5.05 & 16.51 & 2.68 & 0.69 & 1.20 & 0.92 \\
\hline
\end{tabular}


This is in agreement with Asikin-Majid et al. [10], in which the selectivity study where thermal reaction or $\mathrm{CaO}$ catalyzed reaction with triolein generates large fraction of light hydrocarbon in a range of $\mathrm{C}_{6}-\mathrm{C}_{16}$. Meanwhile, the commercial catalyst yielded pyrolysis oil with more on diesel range product. The product with high carbon number or high molecular weight resulted in high filter plugging point and high freezing point. Junming et al. [7] reported that the molecular weight had close relationship to the cold flow properties.

\subsubsection{Functional group analysis}

Fourier Transform-Infrared Spectroscopy (FT-IR) analysis in Figure 9 was performed to study the chemical functional groups exhibited in WCO and pyrolysis oil generated using different type of catalysts. The FT-IR spectra of WCO presented in four extremely broad absorption peak at $2925 \mathrm{~cm}^{-1}$ and $2855 \mathrm{~cm}^{-1}, 1746$ $\mathrm{cm}^{-1}$, and $1163 \mathrm{~cm}^{-1}$ which attributed to stretching absorption of $\mathrm{C}-\mathrm{H}$ bond attached to the carbon atom in the palmitic acid and oleic acid, absorption of glyceride carbonyl group $(\mathrm{C}=\mathrm{O})$ and $\mathrm{C}-\mathrm{O}$ group from ester bond, respectively. The summary of IR absorption characteristic for pyrolysis oil is presented in Table 6 [11,23,24].

The appearance of new peaks of $\mathrm{C} \equiv \mathrm{C}$ at $2305 \mathrm{~cm}^{-1}, \mathrm{C}-\mathrm{O}$ stretching at 1286 and 1236 $\mathrm{cm}^{-1}$, and $\mathrm{O}-\mathrm{H}$ bending at $909 \mathrm{~cm}^{-1}$ in the pyrolysis oil indicated the presence of alkyne and carboxylic acid in a small amount. The broad absorption peak at $1746 \mathrm{~cm}^{-1}$ and $1163 \mathrm{~cm}^{-1}$ for the $\mathrm{C}=\mathrm{O}$ and $\mathrm{C}-\mathrm{O}$ stretching in carboxylic acid were obviously observed in WCO spectra which could be referred as progress of deoxygenation cracking reaction. Furthermore, a slight shift in FT-IR Spectra peak at $1714 \mathrm{~cm}^{-1}$ [10] and $1105 \mathrm{~cm}^{-1}$ in pyrolysis oil denoted the $\mathrm{C}=\mathrm{O}$ stretching and $\mathrm{C}-\mathrm{O}$ stretching of carboxylic acid. The lower intensity of these two absorption peaks was due to dwindling amount of car- boxylic acid in the pyrolysis oil generated in catalytic WCO pyrolysis reaction. The appearance of phenol and alcohol could be observed at absorption peak at $3416 \mathrm{~cm}^{-1}$ in pyrolysis oil according to Tanneru and Steele [23].

\subsubsection{Gas composition analysis}

GC-TCD was used to analyze the composition of gas produced from catalytic pyrolysis of WCO. The gas produce was collected using the Tedlar gas bags equipped with rubber septums for certain reaction time at certain temperature. The nitrogen gas was used as a carrier gas in order to give an oxygen-free condition. Based on the result in Table 7 , the general composition gas such as $\mathrm{H}_{2}, \mathrm{O}_{2}, \mathrm{CO}, \mathrm{CH}_{4}$, and $\mathrm{CO}_{2}$ could be detected by using GC-TCD method analysis.

As reported by Dandik and Aksoy [25], the gaseous product generated from catalytic pyrolysis of Canola oil consisted of $\mathrm{H}_{2}, \mathrm{CO}$ and $\mathrm{CO}_{2}$. in addition to saturated and unsaturated hydrocarbons consisting mostly of those in the $\mathrm{C}_{1}$ $\mathrm{C}_{3}$ range. The gaseous product consisted of

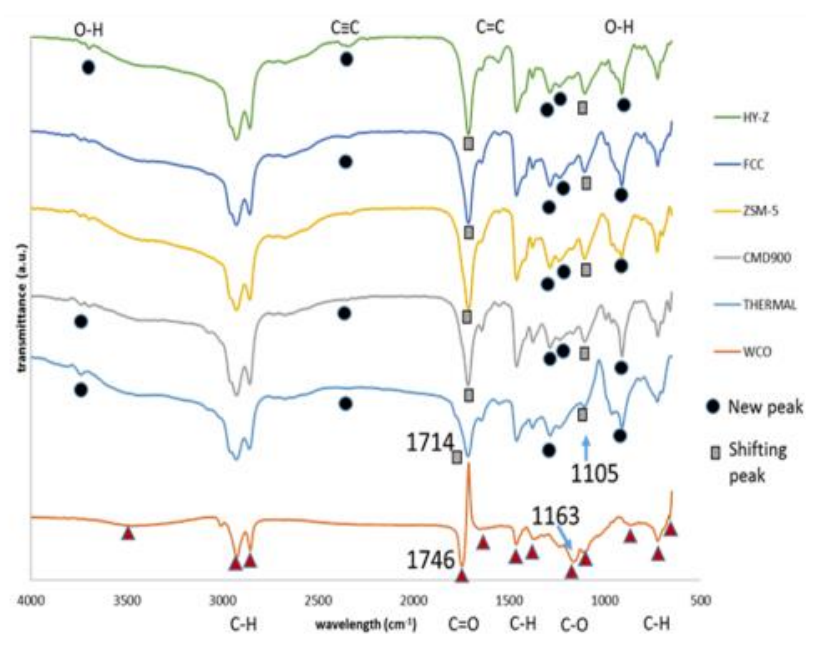

Figure 9. FT-IR spectra result for WCO and pyrolysis oil

Table 5. Composition profile of oxygenated compound in pyrolysis oil

\begin{tabular}{ccccccc}
\hline Catalyst & $\begin{array}{c}\text { Total Oxygenat- } \\
\text { ed Product (\%) }\end{array}$ & Ester (\%) & $\begin{array}{c}\text { Carboxylic } \\
\text { Acid (\%) }\end{array}$ & $\begin{array}{c}\text { Ketone } \\
(\%)\end{array}$ & $\begin{array}{c}\text { Alcohol } \\
(\%)\end{array}$ & $\begin{array}{c}\text { Others } \\
(\%)\end{array}$ \\
\hline Thermal & 35.73 & 0.64 & 23.17 & 1.86 & 7.96 & 2.10 \\
CMD900 & 23.49 & 2.61 & 3.10 & 6.82 & 4.71 & 6.25 \\
ZSM-5 & 48.01 & 0.25 & 35.23 & 2.00 & 9.98 & 0.55 \\
HY-Zeolite & 48.06 & 0.12 & 31.76 & 0.94 & 13.82 & 1.42 \\
FCC & 51.30 & 0.82 & 34.18 & 2.66 & 11.32 & 2.32 \\
\hline
\end{tabular}


high amount of $\mathrm{CO}_{2}$ could be observed in CMD900 > ZSM-5 > Thermal > HY-Zeolite > FCC. Whereas CO content was higher in ZSM$5>$ Thermal $>$ HY-Zeolite $>$ CMD900 $>$ FCC. These two gases namely $\mathrm{CO}_{2}$ and $\mathrm{CO}$ were produced during the decarboxylation and decarbonylation of WCO occurred during the pyrolysis process. These reactions could obviously be observed in composition profile of pyrolysis oil using CMD900 due to lower amount of oxygenated compound present in Table 5.

\section{Conclusion}

Malaysian Dolomite Catalyst $\left(\mathrm{CaMg}\left(\mathrm{CO}_{3}\right)_{2}\right)$ is a potential deoxygenation catalyst for producing biofuel in lighter hydrocarbon $\left(\mathrm{C}_{8}-\mathrm{C}_{24}\right)$ via catalytic pyrolysis of $\mathrm{WCO}$. The calcination with flow of $\mathrm{N}_{2}$.gas at $900{ }^{\circ} \mathrm{C}$, was successfully formed the $\mathrm{MgO}-\mathrm{CaO}$ phase leading to increase catalyst physicochemical properties and capability to absorb more $\mathrm{CO}_{2}$ resulting in lower oxygenated compound (23.49\%) and higher content of liquid hydrocarbon $\left(\mathrm{C}_{8}-\mathrm{C}_{24}, 76.51 \%\right)$ present in pyrolysis oil. The alkane and alkene compounds are observed in the pyrolysis oil through deoxygenation of triglyceride where oxygen content is eliminated via decarboxylation and decarbonylation. In the decarboxylation of heavy oxygenated compounds, alkanes and $\mathrm{CO}_{2}$ are produced, whereas alkenes, water and $\mathrm{CO}$ are produced in the decarbonylation reaction.

\section{Acknowledgements}

The authors acknowledge the financial support from Ministry of Higher Education Malaysia for Fundamental Research Grant Scheme (FRGS/11/TK/UPM/02).

\section{References}

[1] Prado, C.M., Antoniosi Filho, N.R. (2009). Production and Characterization of the Biofuels Obtained by Thermal Cracking and Thermal Catalytic Cracking of Vegetable Oils. Journal of Analytical and Applied Pyrolysis, 86: 338-347.

[2] Khalisanni, K., Khalizani, K., Rohani, M.S., Khalid, P.O. (2008). Analysis of Waste Cooking Oil as Raw Material for Biofuel Production. Global Journal of Environmental Research, 2: 81-83.

Table 6. Summary of FT-IR absorption characteristic for pyrolysis oil

\begin{tabular}{ccc}
\hline Functional Groups & Vibrational Modes Range $\left(\mathrm{cm}^{-1}\right)$ & Pyrolysis Oil Absorption Peak $\left(\mathrm{cm}^{-1}\right)$ \\
\hline O-H stretch & $3200-3600$ & 3416 \\
C-H stretch & $2800-3000$ & 2925,2855 \\
C $\equiv$ C stretch & $2100-2310$ & 2305 \\
C=O stretch & $1670-1820$ & 1714,1712 \\
C=C stretch & $1620-1680$ & 1642 \\
C-H bend & $1350-1470$ & $1375,1460,1462$ \\
C-O stretch & $1000-1320$ & $1105,1164,1236,1286$ \\
C-H bend & $790-1000$ & $807,966,993$ \\
O-H bend & $910-950$ & 909,911 \\
C-H rock & $720-790$ & $720,726,745,785$ \\
\hline
\end{tabular}

Table 7. Composition profile of pyrolysis gas produced from catalytic pyrolysis

\begin{tabular}{cccccc}
\hline Catalyst & Thermal & CMD900 & ZSM-5 & HY-Zeolite & FCC \\
\hline $\mathrm{H}_{2}(\%)$ & 1.73 & 5.69 & 7.25 & 3.60 & 1.15 \\
$\mathrm{O}_{2}(\%)$ & 0.00 & 0.00 & 2.34 & 2.21 & 14.4 \\
$\mathrm{CO}(\%)$ & 7.66 & 3.56 & 9.10 & 4.10 & 1.59 \\
$\mathrm{CH}_{4}(\%)$ & 1.12 & 1.08 & 2.97 & 1.75 & 0.45 \\
$\mathrm{CO}_{2}(\%)$ & 10.91 & 20.56 & 19.51 & 7.67 & 4.46 \\
$\mathrm{~N}_{2}+\mathrm{HCs}$ Gas (\%) & 78.58 & 69.11 & 58.83 & 80.67 & 77.95 \\
\hline
\end{tabular}


[3] Demirbas, A. (2006). Biodiesel Production via Non-catalytic SCF Method and Biodiesel Fuel Characteristics. Energy Conversion and Management, 47: 2271-2282.

[4] Demirbas, A. (2008). New Liquid Biofuels from Vegetable Oils via Catalytic Pyrolysis. Energy Education Science and Technology, 21: $1-59$

[5] Cetinkaya, M., Karaosmanoglu, F. (2004). Optimisation of Base-catalysed Transesterification Reaction of Used Cooking Oil. Energy and Fuels, 18: 1888-1895.

[6] Roh, H.S., Eum, I.H., Jeong, D.W. (2011). The Effect of Calcination Temperature on the Performance of $\mathrm{Ni} / \mathrm{MgO}-\mathrm{Al}_{2} \mathrm{O}_{3}$ Catalysts for Decarboxylation of Oleic Acid. Catalysis Today, 164: 457-460.

[7] Junming, X., Jianchun, J., Jie, C., Yunjuan, S. (2010). Biofuel Production from Catalytic Cracking of Woody Oils. Bioresource Technology, 101: 5586-5591.

[8] Twaiq, F.A., Mohamed, R.A., Bhatia, S. (2003). Liquid Hydrocarbon Fuels from Palm Oil by Catalytic Cracking over Aluminosilicate Mesoporous Catalysts with Various Si/Al Ratio. Microporous and Mesoporous Materials, 64: 95-107.

[9] Wiggers, V.R., Meier, H.F., Wisniewski, A., Chivanga Barros, A.A., Wolf Maciel, M.R. (2009). Biofuels from Continuous Fast Pyrolysis of Soybean Oil: A Pilot Study. Bioresource Technology, 100: 6570-6577.

[10] Asikin-Mijan, N., Taufiq-Yap, Y.H., Lee, H.V. (2015). Synthesis of Clamshell Derived $\mathrm{Ca}(\mathrm{OH})_{2}$ Nano-particles via Simple Surfactant-hydration Treatment. Chemical Engineering Journal, 262: 1043-1051.

[11] Putun, E. (2010). Catalytic Pyrolysis of Biomass: Effects of Pyrolysis Temperature, Sweeping Gas Flow Rate and MgO Catalyst. Energy, 35:2761-2766.

[12] Ngamcharussrivichai, C., Wiwatnimit, W., Sarinyarak, W. (2007). Modified Dolomite as Catalyst for Palm Kernel Oil Transesterification. Journal of Molecular Catalysis A: Chemical, 276: 24-33.

[13] Lu, L., Kejing, Q., Junming, X., Fusheng, L., Shiwei, L., Shitao, Y., Congxia, X., Baoquqn, Z., Xiaoping, G. (2013). Liquid Hydrocarbon Fuels from Catalytic Cracking of Waste Cooking Oils Using Basic Mesoporous Molecular Sieves $\mathrm{K}_{2} \mathrm{O} / \mathrm{Ba}-\mathrm{MCM}-41$ as Catalysts. ACS Sustainable Chemical \& Engineering, 1: 14121416.

[14] Taufiq-Yap, Y.H., Nur-Rizal, A.R., Sivasangar, S., Hussein, M.Z., Aishah, A. (2014). Modification of Malaysian Dolomite Using Mechanochemical Treatment via Different
Media for Oil Palm Fronds Gasification. International Journal of Energy Research, 38: 1008-1015.

[15] Mohammed, M.A.A., Salmiaton, A., Wan Azlina, W.A.K.G., Mohamad Amran, M.S., Taufiq Yap, Y.H. (2013). Preparation and Characterization of Malaysian Dolomites as Tar Cracking Catalyst in Biomass Gasification Process. Journal of Energy, 791582: 1-8.

[16] Yoosuk, B., Udomsap, P., Puttasawat, B. (2001). Hydration-dehydration Technique for Property and Activity Improvement of Calcined Dolomite in Heterogeneous Biodiesel Production: Structural Transformation Aspect. Applied Catalysis A: General, 395: 8794.

[17] Degnan, T.F. (2000). Applications of Zeolite in Petroleum Refining. Top Catalysis, 13: 349356.

[18] Lee, K.H., Shin, D.H. (2003). Catalytic Degradation of Waste HDPE over Acidic Catalyst with Different Pore Sizes. Journal of Industrial and Engineering Chemistry, 9: 584-589.

[19] Srinakruang, J., Sato, K., Vitidsant, T., Fujimoto, K. (2006). Highly Efficient Sulfur and Cooking Resistance Catalysts for Tar Gasification with Steam. Fuel, 85: 2419-2426.

[20] Maher, K.D., Bressler, D.C. (2007). Review: Pyrolysis of Triglyceride Materials for the Production of Renewable Fuels and Chemicals. Bioresource Technology, 98: 2351-2368.

[21] Stendardo, S., Foscolo, P. (2009). Carbon Dioxide Capture with Dolomite: A Model for Gas-Solid Reaction within the Grains of Particulate Sorbent. Chemical Engineering Science, 64: 2343-2352.

[22] Felice, L.D., Courson, C., Foscolo, P., Kiennemann, A. (2011). Iron and Nickel Doped Alkaline-earth Catalysts for Biomass Gasification with Simultaneous Tar Reformation and $\mathrm{CO}_{2}$ Capture. International Journal of Hydrogen Energy, 36: 5296-5310.

[23] Tanneru, S.K., Steele, P.H. (2015). Production of Liquid Hydrocarbons from Pretreated Bio-oil via Catalytic Deoxygenation with Syngas. Renewable Energy, 80: 251-258.

[24] Kamil, F.H., Salmiaton, A., Shahruzzaman, R.M.H.R., Omar, R., Alsultsan, A.G. (2017). Characterization and Application of Aluminum Dross as Catalyst in Pyrolysis of Waste Cooking Oil. Bulletin of Chemical Reaction Engineering and Catalysis, 12: 81-88.

[25] Dandik, L., Aksoy, H.A. (1998). Pyrolysis of Used Sunflower Oil in the Presence of Sodium Carbonate by Using Fractionating Pyrolysis Reactor. Fuel Process Technology, 57: 8192. 